\title{
2020 Hong Kong College of Obstetricians and Gynaecologists guideline on investigations of premenopausal women with abnormal uterine bleeding
}

\author{
Jacqueline HS Lee, Edith OL Cheng, KM Choi, SF Ngu, Rachel YK Cheung * \\ for the Hong Kong College of Obstetricians and Gynaecologists
}

\section{A B S T R A C T}

Abnormal uterine bleeding in premenopausal women is a common gynaecological symptom and composes of abnormality in the frequency, duration, regularity, and flow volume of menstruation. It could constitute the presentation of various gynaecological malignancies. An appropriate history and physical examination are mandatory to ascertain the diagnosis. Depending on the clinical condition, a complete blood picture, thyroid function test, clotting profile, chlamydia test, cervical smear, and pregnancy test can be performed. Ultrasound should be performed in cases with a pelvic mass, unsatisfactory physical examination, persistent symptoms, or no response to medical treatment. In women aged $\geq 40$ years, an out-patient endometrial biopsy with Pipelle should be performed. In women aged $<40$ years with risk factors for endometrial cancer, persistent symptoms, or no response to medical treatment, an endometrial biopsy should be performed to rule out endometrial cancer. Hysteroscopy or saline infusion sonohysterography is more sensitive than ultrasound for diagnosing endometrial pathology. Details of the above recommendations are presented.

\section{Hong Kong Med J 2020;26:520-5 https://doi.org/10.12809/hkmj208897}
JHS Lee, FHKCOG, FHKAM (Obstetrics and Gynaecology)
${ }^{2}$ EOL Cheng, FHKCOG, FHKAM (Obstetrics and Gynaecology)
${ }^{3}$ KM Choi, FHKCOG, FHKAM (Obstetrics and Gynaecology)
${ }^{4}$ SF Ngu, FHKCOG, FHKAM (Obstetrics and Gynaecology)
1,5 RYK Cheung *, FHKCOG, FHKAM (Obstetrics and Gynaecology)
Department of Obstetrics and Gynaecology, The Chinese University of Hong Kong, Hong Kong
Department of Obstetrics and Gynaecology, United Christian Hospital, Hong Kong
Department of Obstetrics and Gynaecology, Pamela Youde Nethersole Eastern Hospital, Hong Kong
${ }^{4}$ Department of Obstetrics and Gynaecology, The Hong Kong University of Hong Kong, Hong Kong
Chairman, HKCOG Guideline Sub-committee
*Corresponding author: rachelcheung@cuhk.edu.hk

\section{Introduction}

Abnormal uterine bleeding (AUB) is a common problem in gynaecological practice and represents a major proportion of out-patient attendance. A postal survey in the United Kingdom found that AUB and its subgroup, heavy menstrual bleeding, affected $15 \%$ to $25 \%$ of women aged 18 to 54 years. ${ }^{1}$ In Hong Kong, the prevalence of AUB is not available, but the following reference provides some information. According to the 2014 Hong Kong College of Obstetricians and Gynaecologists Territory Wide Audit, the numbers of hospital admissions with the diagnoses of 'menorrhagia' and 'dysfunctional uterine bleeding' were 4080 and 3806, respectively. There were 6455 diagnostic hysteroscopies and 3075 hysteroscopic procedures conducted. ${ }^{2}$ Of all operative hysteroscopic procedures performed, the numbers of polypectomies and myomectomies were $2468(80 \%)$ and $380(12 \%)$, respectively. ${ }^{2}$ Although many patients with AUB might not require admission, the case volume mentioned in the above report may reflect the scope of the problem locally.

As patterns of investigation became diversified, a guideline on AUB was considered necessary. Premenopausal women are targeted by this guideline. Postmenopausal bleeding is caused by a different disease spectrum and is not included in this guideline.

\section{Definitions and initial investigations of abnormal uterine bleeding}

The International Federation of Gynecology and Obstetrics classifies AUB in the reproductive years into chronic versus acute non-gestational AUB. ${ }^{3}$ Chronic non-gestational AUB is defined as bleeding from the uterine corpus that is abnormal in frequency, duration, regularity, and/or volume (Table 1) and has been present for the majority of the preceding 6 months. Acute AUB is defined as an episode of heavy bleeding that, in the clinician's opinion, is of sufficient quantity to require immediate intervention to minimise or prevent further blood loss. Menorrhagia is heavy cyclical menstrual blood loss over several consecutive cycles without any 
intermenstrual or postcoital bleeding (ie, without cycle disturbance). The National Institute for Health and Care Excellence (NICE) defines heavy menstrual bleeding as excessive menstrual loss that interferes with a woman's physical, social, emotional, and/or material quality of life. ${ }^{4}$ Intermenstrual bleeding, premenstrual and postmenstrual spotting, and perimenopausal bleeding can be considered as dysfunctional uterine bleeding after exclusion of organic causes.

Obtaining an accurate menstrual history is mandatory to guide the clinician's diagnosis and understand the impact on a woman's quality of life (online supplementary Appendix 1). On general examination, any pallor or thyroid gland enlargement should be noted. If there are features suggestive of thyroid dysfunction or coagulopathy from history or physical examination, a thyroid function test or coagulopathy screening can be ordered accordingly. History suggestive of coagulopathy includes heavy menstrual bleeding since menarche, a family history of coagulopathy, easy bruising, bleeding of the gums, and epistaxis. However, routine thyroid function tests or coagulopathy screening are not recommended in all patients with menorrhagia. Speculum or bimanual examination could elucidate the causes for abnormal bleeding, such as cervical polyps, cervical carcinoma, uterine fibroids, adenomyosis, or ovarian tumours (online supplementary Appendix 1). The following investigations can be arranged depending on the clinical situation: (1) complete blood count to look for anaemia; (2) pregnancy test; (3) ultrasound scan, especially if physical examination suggests a pelvic mass; (4) endometrial assessment; (5) cervical smear if due; and (6) chlamydia screening in cases of postcoital or intermenstrual bleeding.

\section{Endometrial assessment}

There are five main methods of endometrial assessment: ultrasound scanning, magnetic resonance imaging (MRI), endometrial biopsy or aspirate, hysteroscopy, and dilatation and curettage $(\mathrm{D} \& \mathrm{C})$ under various modes of anaesthesia.

\section{Ultrasound scanning}

Ultrasound scanning, particularly the transvaginal route, is used to assess endometrial thickness, endometrial and myometrial consistency, and abnormalities of the endometrial lining (eg, submucosal fibroids or polyps). However, most studies have investigated the endometrial thickness of postmenopausal women. Smith-Bindman et $\mathrm{al}^{5}$ observed that the average endometrial thicknesses were $4 \mathrm{~mm}, 10 \mathrm{~mm}, 14 \mathrm{~mm}$, and $20 \mathrm{~mm}$ in normal postmenopausal women, those with endometrial polyps, those with endometrial hyperplasia, and those with endometrial carcinoma, respectively.
香港婦產科學院2020年婦女停經前子宮出血 異常調查指南

李影思、鄭愛玲、蔡嘉敏、吳庥慧、張優嘉

婦女停經前出現子宮異常出血是婦科的常見症狀，包括月經頻率、持 續時間, 規律性或流量異常, 可能導致各種婦科惡性腫瘤。為了確定 診斷, 適當的病史和體格檢查是必須的。根據臨床情況可以進行全血 檢查、甲狀腺功能檢查、凝血指數、衣原體檢查, 宮頸塗片檢查和妊 娠檢查。出現盆腔腫塊、體檢結果不合格、症狀持續或對醫療無反應 時應進行超聲檢查。40歲或以上女性應進行Pipelle子宮內膜活檢。 40 歲以下女性如有子宮內膜癌、持續症狀或對藥物治療無反應等危險 因素，應進行子宮內膜活檢以排除子宮內膜癌。宮腔鏡檢查或生理鹽 水輸注宮腔造影比超聲對子宮內膜病變的診斷更為敏感。本文對以上 建議提供詳細信息

TABLE I. Abnormal uterine bleeding symptoms according to the International Federation of Gynecology and Obstetrics

\begin{tabular}{|c|c|}
\hline Frequency & $\begin{array}{l}\text { Absent (no bleeding) = amenorrhoea } \\
\text { Infrequent }(>38 d) \\
\text { Normal }(\geq 24 \text { to } \leq 38 d) \\
\text { Frequent }(<24 d)\end{array}$ \\
\hline Duration & $\begin{array}{l}\text { Normal }(\leq 8 \mathrm{~d}) \\
\text { Prolonged }(>8 \mathrm{~d})\end{array}$ \\
\hline Regularity & $\begin{array}{l}\text { Normal or regular (shortest to longest cycle variation: } \leq 7-9 d^{*} \\
\text { Irregular (shortest to longest cycle variation: } \geq 8-10 \mathrm{~d} \text { ) }\end{array}$ \\
\hline $\begin{array}{l}\text { Flow volume } \\
\text { (patient- } \\
\text { determined) }\end{array}$ & $\begin{array}{l}\text { Light } \\
\text { Normal } \\
\text { Heavy }\end{array}$ \\
\hline
\end{tabular}

However, the prediction of endometrial pathology based on ultrasound results in premenopausal women was not reliable because of the great overlap between the normal range and that of women with endometrial pathology.

The NICE guideline ${ }^{4}$ recommends that in patients with examination suggestive of fibroids, a pelvic ultrasound should be performed. Depending on the size of the uterus, transvaginal or transabdominal ultrasonography could be performed. Transvaginal ultrasonography produces better image quality because of its higher frequency, which allows greater image resolution at the expense of decreased depth of penetration. In patients in whom physical examination is impossible or unsatisfactory, or symptoms persist despite medical treatment, an ultrasound should also be arranged. Pelvic ultrasound can be useful for detecting gross endometrial or myometrial pathology such as fibroids and adenomyosis. However, pelvic ultrasonography does not replace an endometrial biopsy.

In cases where vaginal access is difficult or 


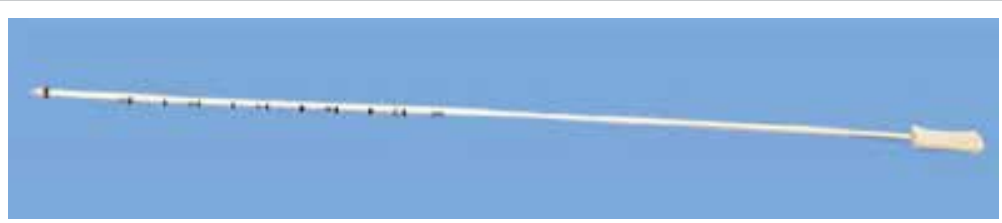

FIG. The Pipelle is the most commonly used endometrial sampling device in Hong Kong

\section{Endometrial biopsy}

The main purpose of obtaining an endometrial biopsy or endometrial aspirate is to exclude endometrial pathology like hyperplasia, disordered endometrium, or malignancies. Most endometrial biopsies can be performed in out-patient or office clinics and have the advantages of being simple, quick, safe, and convenient and avoiding the need for anaesthesia. Furthermore, the device is disposable, and the procedure is much less costly than conventional D\&C.

The Pipelle is the most common out-patient

TABLE 2. Sensitivity and specificity of endometrial sampling devices for detecting endometrial carcinoma

\begin{tabular}{lcc}
\hline & Sensitivity & Specificity \\
\hline Pipelle $^{11,12}$ & $86 \%-97.5 \%$ & $100 \%$ \\
Novak $^{16,17}$ & $50 \%-85 \%$ & $97 \%$ \\
Tis-u-Trap $^{17}$ & - & $92 \%$ \\
Vabra aspirator $^{17}$ & $100 \%$ & $87.7 \%$ \\
Tao Brush $^{11}$ & $95.5 \%$ & $100 \%$ \\
Cytospat $^{17}$ & $60 \%$ & $100 \%$ \\
Explora $^{18}$ & $90.6 \%$ & $100 \%$ \\
\hline Z-sampler & $82.5 \%$ & - \\
\hline
\end{tabular}

impossible, such as in adolescents and virgin girls, transrectal ultrasonography should be offered. This technique has been shown to provide better image quality compared with the transabdominal route without causing significant discomfort to patients. ${ }^{6}$

Saline infusion sonohysterography (SIS) involves the instillation of 5 to $15 \mathrm{~mL}$ of normal saline into the uterine cavity and may allow better detection of endometrial polyps and submucosal fibroids. A 2017 meta-analysis concluded that twodimensional SIS is highly sensitive for detection of endometrial polyps and submucosal uterine fibroids, with pooled sensitivity values of $93 \%$ and $94 \%$ and specificity of $81 \%$ and $81 \%$, respectively. ${ }^{7}$ Clinicians may consider SIS in cases where further evaluation of endometrial lesions is required.

\section{Magnetic resonance imaging}

Magnetic resonance imaging has been shown to be more sensitive than transvaginal ultrasound (TVS) for the identification of fibroids, especially the growth of submucosal fibroids into the uterine cavity. ${ }^{8}$ Magnetic resonance imaging is slightly more sensitive than TVS for diagnosing adenomyosis (sensitivity: $77 \%$ vs $72 \%$ ). ${ }^{9,10}$ However, the chance of identifying important additional findings by MRI over ultrasound has to be weighed against the waiting time and cost of MRI. Magnetic resonance imaging should not be the routine for all cases of AUB. In cases where vaginal access is difficult or impossible, or when it is difficult to differentiate between fibroids and adenomyosis, there is a role for MRI. endometrial assessment device used in the United Kingdom and Hong Kong (Fig). Other devices includes Novak (a silastic cannula with a beveled lateral opening), Tis-u-Trap (a plastic curette with suction), the Vabra aspirator (a cannula connected to a vacuum pump), Endorette (a plastic cannula with multiple openings), Tao Brush (a sheath brush device), Cytospat (a polypropylene cannula with a rhomboid head), Accurette (a quadrilateral-shaped curette with four cutting edges), Explora (a plastic curette with a Randall-type cutting edge), and Z-sampler (a flexible polypropylene device). A metaanalysis including 60 articles found that Pipelle performs as well as D\&C and as well as or better than other endometrial sampling devices in terms of sampling adequacy and sensitivity. Pipelle seems to be better than the other options in terms of pain/ was consistently high for Pipelle, mostly $>85 \%$, compared with $98 \%$ for D\&C. ${ }^{11}$ Pipelle's specimen adequacy rate and concordance rate to histology on hysterectomy were similar to those of $D \& C$. Pipelle biopsy is reliable for excluding endometrial carcinoma: previous studies showed that Pipelle detected $98 \%$ of endometrial carcinomas. ${ }^{12}$

The Vabra device can sample a larger proportion of the endometrium (42\%) compared with Pipelle (4\%). ${ }^{13}$ However, other studies did not find a better specimen adequacy rate of the Vabra device over Pipelle ${ }^{14,15}$ (Table $2^{11,12,16-18}$ ).

Endometrial cancer is thought to be uncommon in women aged $<40$ years, and this matches the reported local experience..$^{19}$ In 2017, the Hong Kong Cancer Registry report showed that out of a total of 1076 new cases of cancer of the endometrial corpus, only 47 cases $(4.4 \%)$ occurred in women aged $<40$ years. ${ }^{19}$ Although endometrial cancer is uncommon in women aged $<40$ years, its incidence is increasing. In 2017, the age-specific incidences for endometrial carcinoma in various age-groups were $4,9,18,66$, and 64 per 100000 women at ages 30,35 , 40,50 , and 55 years, respectively, with the incidence peaking at ages 50 to 54 years..$^{19}$ In 2007 , the figures were 2 and 6 per 100000 women at ages 30 and 35, respectively.

At what age should the gynaecologist perform discomfort and costs. ${ }^{11}$ The sample adequacy rate 
endometrial biopsy? It had been suggested that routine endometrial biopsy is not necessary for AUB in women aged $<40$ years. However, in view of the increasing incidence of endometrial cancers among younger women, an endometrial assessment is warranted for women aged $<40$ years who present with AUB and also have other high-risk features (Table 3). Instead of arbitrarily choosing an age at which endometrial biopsy should or should not be done, the woman's risk of endometrial carcinoma should be assessed. When they present with AUB, women at high risk of endometrial cancer need endometrial biopsy regardless of age. Therefore, Hong Kong College of Obstetricians and Gynaecologists recommends endometrial biopsy in all women with AUB aged $\geq 40$ years and in women with risk factors for endometrial carcinoma irrespective of age. Patients with persistent symptoms or in whom medical treatments have failed should also undergo endometrial biopsy.

\section{Hysteroscopy}

Hysteroscopy allows direct visualisation of the whole endometrial cavity, lower segment, and cervical canal. Hysteroscopy can detect small polyps or submucosal fibroids and provide an opportunity for endometrial biopsy without the need for general anaesthesia. The NICE guideline recommends out-patient hysteroscopy for women with uterine cavity abnormalities or when endometrial pathology is suspected because it is more accurate than pelvic ultrasound. ${ }^{4}$ A Hong Kong study showed that out-patient hysteroscopy was successful in $92 \%$ of patients. ${ }^{20}$ Prospective studies have shown that diagnostic hysteroscopy had significantly better diagnostic performance than SIS and TVS. ${ }^{16}$ The sensitivity and specificity for any uterine abnormality of SIS and TVS were $92 \%$ and $89 \%$ versus $60 \%$ and $56 \%$, respectively. The sensitivity and specificity for diagnostic hysteroscopy were $97 \%$ and $92 \%$, respectively. ${ }^{21}$ The patients' acceptability was high, and the failure

TABLE 3. Risk factors for endometrial cancer

\begin{tabular}{l}
\hline Obesity \\
Polycystic ovarian syndrome \\
Lynch syndrome \\
Family history of gynaecological and gastrointestinal \\
malignancy \\
Unopposed oestrogen therapy \\
Tamoxifen therapy \\
Persistent or long-standing abnormal uterine bleeding \\
No response to medical treatment \\
\hline
\end{tabular}

rate was low, with failure mainly occurring due to pain during the procedure, distorted uterine cavity, and tight cervical os, especially in postmenopausal and nulliparous patients. The last problem can be partially overcome by using a hysteroscope of smaller diameter (minihysteroscopy). A 'no touch' approach with vaginoscopy has been shown to be quicker, less painful, and more successful than standard hysteroscopy and can be considered for out-patient hysteroscopy. ${ }^{22}$

A randomised controlled trial ${ }^{23}$ comparing TVS, out-patient hysteroscopy, and endometrial biopsy with in-patient hysteroscopy and D\&C showed that a combination of transvaginal scan, Pipelle endometrial biopsy, and out-patient hysteroscopy had similar efficacy to in-patient hysteroscopy and $\mathrm{D} \& \mathrm{C}$ for the investigation of AUB. Transvaginal scan and endometrial biopsy can therefore be considered as the first-line investigation, followed by out-patient hysteroscopy. ${ }^{24}$

Some authors have suggested that a normal cavity on hysteroscopy obviates the need for an endometrial biopsy. However, normal hysteroscopy findings are not conclusive of the absence of premalignant or malignant lesions and do not eliminate the need for endometrial sampling, as they do not substitute for benign histological examination findings. ${ }^{25}$

\section{Dilatation and curettage}

Dilatation and curettage, and the endometrial histology obtained by that method, were previously considered as the 'gold standard' in AUB management. However, multiple studies showed that $D \& C$ is not superior to endometrial assessment with Pipelle or other out-patient endometrial assessment devices, and $\mathrm{D} \& \mathrm{C}$ requires general anaesthesia. ${ }^{11}$ Dilation and curettage only should no longer be the gold standard in endometrial pathological assessment, but D\&C with concurrent hysteroscopy may be useful when intrauterine lesions are suspected, as it allows direct visual assessment of the endometrial cavity. For patients in whom outpatient hysteroscopy or endometrial biopsy is not possible, in-patient hysteroscopy and $D \& C$ under general anaesthesia should be offered, but $\mathrm{D} \& \mathrm{C}$ does not have therapeutic value in AUB except for temporarily stopping heavy menstrual bleeding.

\section{Summary of recommendations}

1. The chance of endometrial carcinoma in women aged $<40$ years is low. However, endometrial assessment is warranted if there are risk factors for endometrial carcinoma, if symptoms are persistent/long-standing, or symptoms fail to respond to medical treatment (Grade B).

2. Pelvic ultrasound (preferably TVS) and 
endometrial sampling with Pipelle are the preferred first-line methods of assessing AUB. Hysteroscopy is indicated if uterine cavity abnormalities are suspected (Grade B).

3. Out-patient hysteroscopy is safe and reliable and should be the preferred setting for diagnostic hysteroscopy (Grade A).

4. Routine first-line D\&C should be discouraged. Dilation and curettage should be reserved for women requiring general anaesthesia for other indications (Grade A).

A summary of the recommendations are shown in the online supplementary Appendix 2 .

\section{Author contributions}

Concept or design: All authors.

Acquisition of data: JHS Lee, EOL Cheng, KM Choi, SF Ngu. Analysis or interpretation of data: JHS Lee, EOL Cheng, KM Choi, SF Ngu.

Drafting of the manuscript: All authors.

Critical revision of the manuscript for important intellectual content: All authors.

All authors had full access to the data, contributed to the study, approved the final version for publication, and take responsibility for its accuracy and integrity.

\section{Conflicts of interest}

All authors have disclosed no conflicts of interest.

\section{Acknowledgement}

This guideline was produced by the Hong Kong College of Obstetricians and Gynaecologists as an educational aid and reference for obstetricians and gynaecologists practising in Hong Kong. The guideline does not define a standard of care, nor is it intended to dictate an exclusive course of management. It presents recognised clinical methods and techniques for consideration by practitioners for incorporation into their practice. It is acknowledged that clinical management may vary and must always be responsive to the needs of individual patients, resources, and limitations unique to the institution or type of practice. Particular attention is drawn to areas of clinical uncertainty in which further research may be indicated.

\section{Declaration}

The content of this guideline has been published in the Hong Kong College of Obstetricians and Gynaecologists Guidelines Number 5, revised July 2020 (http://www.hkcog. org.hk/hkcog/Download/Guideline_on_investigations_of_ premenopausal_women_with_abnormal_uterine_bleeding. pdf). This is a revised version of the 2001 Hong Kong College of Obstetricians and Gynaecologists guideline on investigations of premenopausal women with abnormal uterine bleeding (http://www.hkcog.org.hk/hkcog/Download/Abnormal\%20 uterine\%20bleeding_2001.pdf).

\section{Funding/support}

This medical practice paper received no specific grant from any funding agency in the public, commercial, or not-forprofit sectors.

\section{References}

1. Shapley M, Jordan K, Croft PR. An epidemiological survey of symptoms of menstrual loss in the community. Br J Gen Pract 2004;54:359-63.

2. Hong Kong College of Obstetricians \& Gynaecologists. Territory-wide audit in obstetrics \& gynaecology. 2014. Available from: http://www.hkcog.org.hk/hkcog/ Download/Territory-wide_Audit_in_Obstetrics_ Gynaecology_2014.pdf. Accessed 1 May 2020.

3. Munro MG, Critchley HO, Fraser IS, FIGO Menstrual Disorders Committee. The two FIGO systems for normal and abnormal uterine bleeding symptoms and classification of causes of abnormal uterine bleeding in the reproductive years: 2018 revisions. Int J Gynaecol Obstet 2018;143:393408.

4. National Institute for Health and Care Excellence. Heavy menstrual bleeding: assessment and management NICE guideline [NG88]. 2018. Available from: https://www.nice. org.uk/guidance/ng88. Accessed 25 Feb 2020.

5. Smith-Bindman R, Kerlikowska K, Feldstein V, et al. Endovaginal ultrasound to exclude endometrial cancer and other endometrial abnormalities. JAMA 1998;280:1510-7.

6. Timor-Tritsch IE, Monteagudo A, Rebarber A, Goldstein SR, Tsymbal T. Transrectal scanning: an alternative when transvaginal scanning is not feasible. Ultrasound Obstet Gynecol 2003;21:473-9.

7. Bittencourt CA, Dos Santos Simões R, Bernardo WM, et al. Accuracy of saline contrast sonohysterography in detection of endometrial polyps and submucosal leiomyomas in women of reproductive age with abnormal uterine bleeding: systematic review and meta-analysis. Ultrasound Obstet Gynecol 2017;50:32-9.

8. Dueholm M, Lundorf E, Hansen ES, Ledertoug S, Olesen F. Evaluation of the uterine cavity with magnetic resonance imaging, transvaginal sonography, hysterosonographic examination, and diagnostic hysteroscopy. Fertil Steril 2001;76:350-7.

9. Bazot M, Daraï E. Role of transvaginal sonography and magnetic resonance imaging in the diagnosis of uterine adenomyosis. Fertil Steril 2018;109:389-97.

10. Champaneria R, Abedin P, Daniels J, Balogun M, Khan KS. Ultrasound scan and magnetic resonance imaging for the diagnosis of adenomyosis: systematic review comparing test accuracy. Acta Obstet Gynecol Scand 2010;89:137484 .

11. Narice BF, Delaney B, Dickson JM. Endometrial sampling in low-risk patients with abnormal uterine bleeding: a systematic review and meta-synthesis. BMC Fam Pract 2018 30;19:135.

12. Stovall G, Photopulos GJ, Poston WM, Ling FW, Sandles LG. Pipelle endometrial sampling in patients with known endometrial carcinoma. Obstet Gynecol 1991;77:954-6.

13. Rodriguez GC, Yaqub N, King ME. A comparison of the Pipelle device and Vabra aspirator as measured by endometrial denudation in hysterectomy specimens: the Pipelle samples significantly less of the endometrial surface than the Vabra aspirator. Am J Obstet Gynecol 1993;168:55-9.

14. Eddowes HA, Read MD, Codling BW. Pipelle: a more acceptable technique for outpatient endometrial biopsy. $\mathrm{Br}$ J Obstet Gynaecol 1990;97:961-2.

15. Naim NM, Mahdy ZA, Ahmad S, Razi ZR. The Vabra aspirator versus the Pipelle device for outpatient 
endometrial sampling. Aust $\mathrm{N} \mathrm{Z} \mathrm{J} \mathrm{Obstet} \mathrm{Gynaecol}$ 2007;47:132-6

16. Larson DM, Krawisz BR, Johnson KK, Broste SK. Comparison of the Z-sampler and Novak endometrial biopsy instruments for in-office diagnosis of endometrial cancer. Gynecol Oncol 1994;54:64-7.

17. Antoni J, Folch E, Costa J, et al. Comparison of Cytospat and Pipelle endometrial biopsy instruments. Eur J Obstet Gynecol Reprod Biol 1997;72:57-61.

18. Kufahl J, Pedersen I, Sindberg Eriksen P, et al. Transvaginal ultrasound, endometrial cytology sampled by Gynoscann and histology obtained by Uterine Explora Curette compared to the histology of the uterine specimen. A prospective study in pre- and postmenopausal women undergoing elective hysterectomy. Acta Obstet Gynecol Scand 1997;76:790-6.

19. Hong Kong Cancer Registry, Hospital Authority, Hong Kong SAR Government. Cancer incidence and mortality report in Hong Kong. 2016-2017 Available from: www3. ha.org.hk/cancereg, Assessed 25 Feb 2020.

20. Lo KW, Yuen PM. The role of outpatient diagnostic hysteroscopy in identifying anatomic pathology and histopathology in the endometrial cavity. J Am Assoc
Gynecol Laparosc 2000;7:381-5.

21. Grimbizis GF, Tsolakidis D, Mikos T, et al. A prospective comparison of transvaginal ultrasound, saline infusion sonohysterography, and diagnostic hysteroscopy in the evaluation of endometrial pathology. Fertil Steril 2010;94:2720-5.

22. Smith PP, Kolhe S, O'Connor S, Clark TJ. Vaginoscopy against standard treatment: a randomised controlled trial. BJOG 2019;126:891-9.

23. Tahir MM, Bigrigg MA, Browning JJ, Brookes ST, Smith PA. A randomised controlled trial comparing transvaginal ultrasound, outpatient hysteroscopy and endometrial biopsy with inpatient hysteroscopy and curettage. Br J Obstet Gynaecol 1999;106:1259-64.

24. Bain C, Parkin DE, Cooper KG. Is outpatient diagnostic hysteroscopy more useful than endometrial biopsy alone for the investigation of abnormal uterine bleeding in unselected premenopausal women? A randomised comparison. BJOG 2002;109:805-11.

25. Bakour SH, Dwarakanath LS, Khan KS, Newton JR. The diagnostic accuracy of outpatient miniature hysteroscopy in predicting premalignant and malignant endometrial lesions. Gynaecol Endosc 1999;8:143-8. 